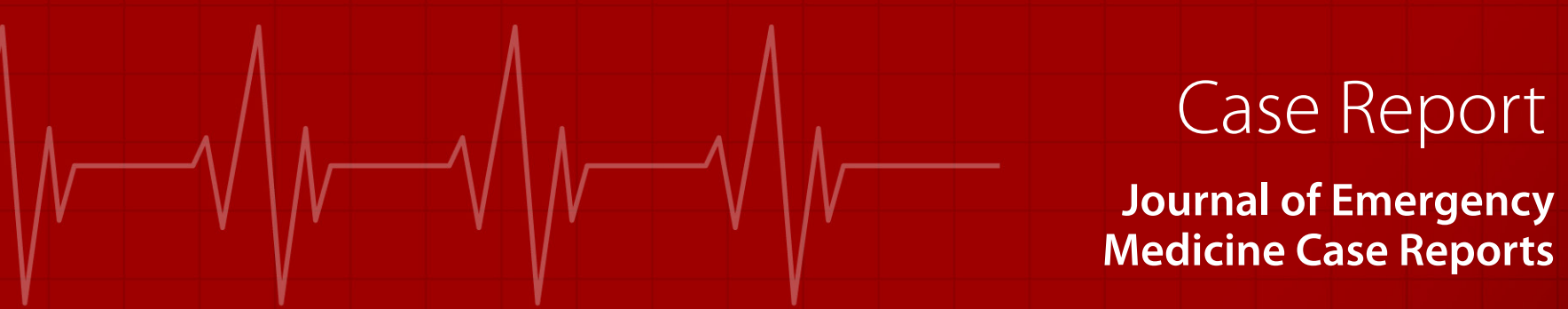

\title{
Idiopathic Isolated Hypoglossal Nerve Palsy: Case Report
}

Selim Tetik', Oya Güven², Mehmet Çoban ${ }^{3}$

${ }^{1}$ Kırklareli Training and Research Hospital, Department of Emergency Medicine, Kırklareli Turkey

${ }^{2}$ Kırklareli University School of Medicine, Kırklareli Training and Research Hospital Department of Emergency Medicine, Kırklareli Turkey ${ }^{3}$ Medikent Hospital Otorhinolaryngology Department, Kırklareli Turkey

\section{Abstract}

Introduction: Nerve Hypoglossal, which innervates the tongue muscles; provides language movements, speech and chewing functions. This nerve palsy may develop during tumor, trauma, or infection but idiopathic nerve palsy is rare. In this article; We tried to examine the diagnosis and treatment process of twelfth nerve palsy cases whose cause could not be determined.

Case Report: 16 years old female patient; She applied to our emergency service with the complaint of her tongue turning left in the mouth. In the tests carried out, no reason was found to cause this. The patient was diagnosed with twelfth nerve palsy and treatment was initiated by neurology. The patient recovered after 10 days of treatment.

Conclusion: Twelfth nerve palsy is usually seen with other nerve palsy, isolated twelfth nerve palsy is rare. In this article; We tried to emphasize that this isolated situation may be a harbinger of neurological diseases.

Key Words: Hypoglossal nerve palsy, Tongue diseases, Neurological diseases

\section{Introduction}

The hypoglossal nerve (XII. Nerve, N.Hypoglossus) originates from the bulbus and contains only motor fibers. After these fibers leave the brainstem, they pass through the canalis hypoglossia in the occipital bone to the parapharyngeal space and the occipital artery level. Finally, it comes to the suprahyoid region. It passes behind the mylohyoid and hyoglossus muscles and reaches the intrinsic muscles of the tongue. It also innervates the styloglossus, hyoglossus and genioglossus muscles ${ }^{1,2}$. Any lesion, trauma or infection can cause hypoglossal nerve palsy, both during the bulbus and the nerve trace.

$\mathrm{N}$. Hypoglossus, which innervates the tongue muscles; Provides language movements, speech and chewing functions. It gives segments in the medullary (nuclear), cisternal (extramedullary intracranial), skull base (hypoglossal canal), oropharyngeal, nasopharyngeal (close to the 9th and 10th nerves and the internal carotid artery) and sublingual space along the nerve trace. Therefore, it can be damaged due to many etiological reasons, which vary according to its segments throughout its course ${ }^{3}$. Lesions of $\mathrm{N}$. hypoglossus are usually seen with other cranial nerves in close neigh- borhood. In Collet-Sicard syndrome IX., X., XI. and XII. in cranial nerves; Villaret's syndrome IX., X., XI. and XII. cranial nerves, plexus sympathicus and sometimes VII. in the cranial nerve; In Jackson syndrome X., XI. and XII. in cranial nerves; In Tapia's syndrome, the X. and XII. In addition to cranial nerves, sometimes XI. lesions are seen in the cranial nerve.

A tongue examination is performed to detect N.hypoglossus lesions. During the examination; The shape of the tongue at rest, its protrusion forward in the midline, other movements and muscle volume are examined. Sensory pathology is not observed in N. hypoglossus lesions. The most basic way to distinguish $\mathrm{N}$. hypoglossus lesions is to move the tongue forward by asking to examine the function of the M. genioglossus. In the unilateral loss of function of $\mathrm{M}$. genioglossus, the tongue deviates to the side of the loss of function while advancing forward ${ }^{4}$.

\section{Case Report}

A 16-year-old female patient admitted to our emergency room with the complaint of her tongue turning left (not ro- 


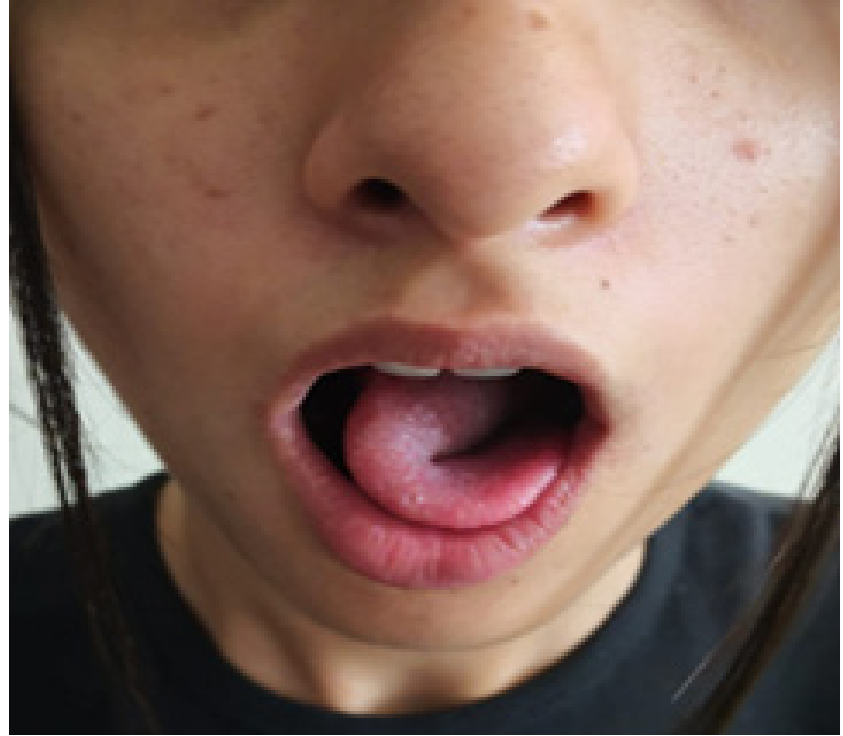

Figure-1: Tongue was observed turn to left-handed inside the mouth

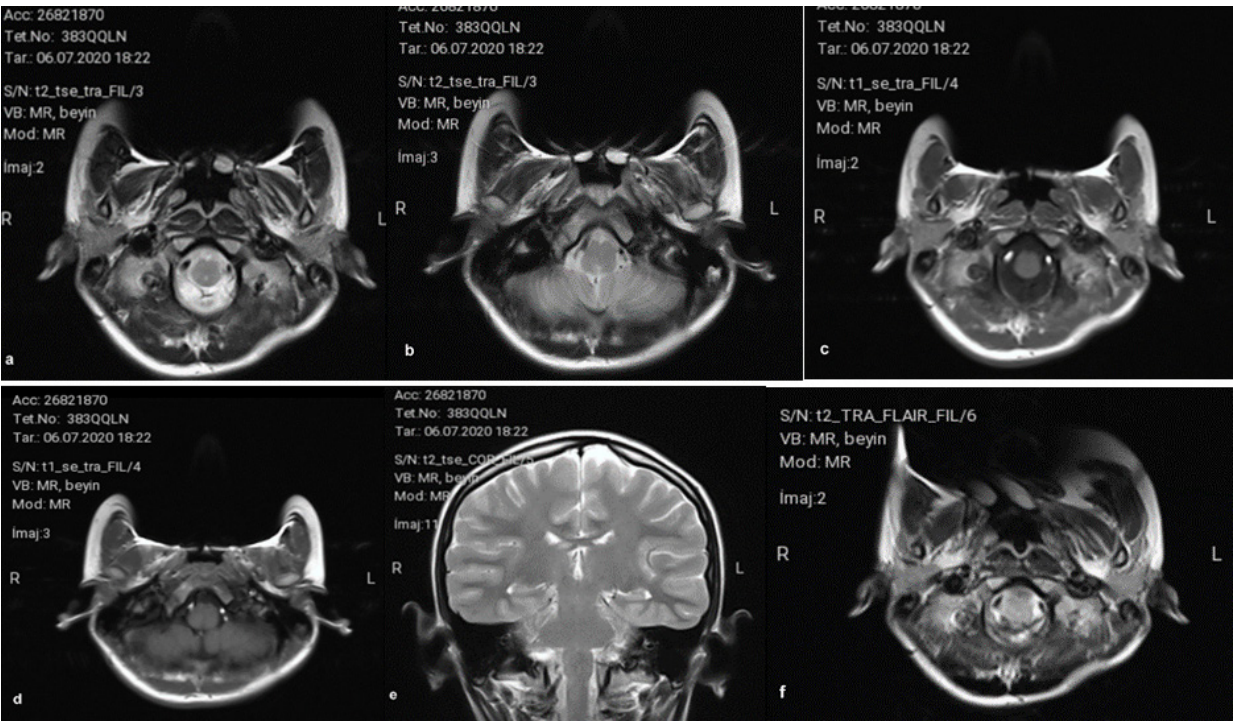

Figure-2(a-b-c-d-e-f): Brain MRI showing the normal course of the hypoglossus nerve

tating) in her mouth for 3 days. The general condition was good, orientated, cooperative. There was no risk of pregnancy or a history of smoking and alcohol abuse. Vital signs; blood pressure: 120/60 mm / Hg, pulse: 92 / min, fever: 36.7 degrees measured. On physical examination, when the tongue was released inside the mouth and at rest, it was seen turned to the left; when moving left-right and outside the mouth, normal movements were observed. There was no fasciculation (Figure-1). There was a lisping, especially when she says the letters c, ç, l, n, r in Turkish. Anterior rhinoscopy examination was normal. There was no mass under the tongue and under the mandible in palpation. Other cranial nerve examinations were normal. Motor, sensory and cerebellar system examinations were normal and deep tendon reflexes were normoactive. There was no prominent feature in her background and family history. Blood count, biochemistry panel (including C-Reactive Protein, sedimentation, vitamin $\mathrm{D}$, magnesium, calcium) results were measured within normal limits. Viral serology tests were normal. Brain Magnetic Resonance I maging (MRI) was performed to rule out stroke, demyelinating diseases, space-occupying lesions and infectious causes (such as abscess). It was normal (Figure-2 (a-b-c-d-e-f)). Antipsychotic (haloperidol), dopaminergic (amantadine sulphate), anticholinergic (biperidene hydrochloride), vitamin B12, vitamin D were prescribed by the neurologist. On the 3rd day of treatment, her complaints subsided. On the 10th day, she recovered completely.

The case report has written in an anonymous characteristic, thus secret and detailed data about the patient has removed. Editor and reviewers can know and see these detailed data. These data are backed up by editor and by reviewers. 


\section{Discussion}

Literature research has shown that; in case of isolated Hypoglossal nerve paralysis, Intracranial or extracranial space occupying lesion, head and neck injury (including injuries during intubation and cuff compression), vascular abnormality, infection, autoimmune disease or neuropathy are seen. Reports of idiopathic cases are rare.

When imaging is performed, one of the space-occupying lesions can be detected, except that there are normal imaging findings.

In diagnosis; blood count, sedimentation, C-Reactive Protein, antiviral tests (Ebstein-Barr Virus, Herpes Simplex Virus, Cytomegalo Virus), cancer screening tests can be performed. Brain Computed Tomography (CT), brain MRI should be seen to rule out neurological diseases.

Isolated hypoglossal nerve palsy is rare in the literature. In the article of Combarros et al., Which is the most comprehensive study ever, there are 9 patients. No factors were detected in 4 of these patients. 3 patients had malignancy and 2 patients had arterio-venous malformation. It was emphasized that the number of idiopathic forms is significant and it can also be a sign of malignancy ${ }^{5}$. In our case, it is compatible with the literature as no factor can be detected. In a retrospective study by Keane et al., 12 nerve palsy was also detected in 100 people who were seen with other cranial nerve lesions. 49 of them were from tumor origin and prognosis was poor in these patients with tongue involvement ${ }^{6}$.

Cranial nerve palsy finding in young patients may be a sign for secondary parkinsonism? ${ }^{7}$. The response of our patient to dopaminergic and anticholinergic treatment supports this pre-diagnosis. Although there is no convincing suggestion in the literature about the treatment of this type of cranial nerve paralysis, it has been reported that high dose steroid administration with vitamin complexes (especially vitamin B) accelerates recovery ${ }^{8}$.

Detailed anamnesis, process of the neurological state, knowing the anatomy and physiology of the hypoglossal nerve; It is important when choosing tests for diagnosis. MRI may be a good option to confirm or rule out multiple diagnoses. Even today, most of these patients are misdiagnosed. Because hypoglossal paralysis accompanies other symptoms in general.

\section{Conclusion}

Isolated hypoglossal nerve palsy is rare and should not be considered as a disease alone, it should be used to rule out other diagnoses and followed considering that it is a symptom of another disease. We could not detect any other disease in our patient to explain this situation. However, if we consider that we received a response to treatment, the patient should be followed up for long-term demyelinating diseases

\section{Conflict of Interest}

The authors declare that they have no conflict of interest.

\section{References}

1. Odar V. Anatomi: Hacettepe Taş Kitapçוlık 1986; p:437-438.

2. Janfaza $P$, ed. Surgical anatomy of the head and neck. Harvard University Press; 2011.

3. PeközT, Koç F, Bozdemir H. Orofaringeal manuplasyona bağlı unilateral hipoglossal sinir paralizisi. Cukurova Medical Journal 37.2 (2012); 107-111.

4. Bahşi İ. Baş ve Boyun Anatomisi, XII. Nervus Hypoglossus (CN XII), Editor: Prof. Dr. YA PINAR, 2019. P:264-269

5. Combarros O., Alvarez DA, Berciano J. Isolated unilateral hypoglossal nerve palsy: nine cases. Journal of neurology 245.2 (1998); 98-100.

6. Keane JR. Twelfth-nerve palsy: analysis of 100 cases. Archives of Neurology 53.6 (1996); 561-566.

7. Hoehn MM, Melvin DY. Parkinsonism: onset, progression, and mortality. Neurology 50.2 (1998); 318-318.

8. Lagalla $G$. Influence of early high-dose steroid treatment on Bell's palsy evolution. Neurol Sc (2002); 23. 107-12. 